\title{
Decoupling algorithm for evaluating multiple beam damages in steel moment-resisting frames
}

$\operatorname{AUTHOR}(S):$

Li, Xiaohua; Kurata, Masahiro; Suzuki, Akiko

\section{CITATION:}

Li, Xiaohua ...[et al]. Decoupling algorithm for evaluating multiple beam damages in steel moment-resisting frames. Earthquake Engineering and Structural Dynamics 2017, 46(7): 1045-1064

ISSUE DATE:

2017-06

URL:

http://hdl.handle.net/2433/263902

\section{RIGHT:}

This is the peer reviewed version of the following article:[Decoupling algorithm for evaluating multiple beam damages in steel moment-resisting frames, Earthquake Engineering and Structural Dynamics, 46(7) 1045-1064], which has been published in final form at https://doi.org/10.1002/eqe.3120. This article may be used for non-commercial purposes in accordance with Wiley Terms and Conditions for Use of Self-Archived Versions.; The full-text file will be made open to the public on 18 November 2017 in accordance with publisher's 'Terms and Conditions for Self-Archiving'; This is not the published version. Please cite only the published version. この論文は出版社版でありません。引用の際には出版社 版をご磪認じ利用ください。 


\title{
Decoupling algorithm for evaluating multiple beam damages in steel moment-resisting frames
}

\author{
Xiaohua $\mathrm{Li}^{1}$, Masahiro Kurata ${ }^{1}$, and Akiko Suzuki ${ }^{2}$ \\ ${ }^{1}$ Disaster Prevention Research Institute, Kyoto University, Kyoto, Japan \\ ${ }^{2}$ Department of Architecture and Architectural Engineering, Kyoto University, Kyoto, Japan
}

\section{SUMMARY}

Post-earthquake safety evaluation of steel moment-resisting frames mainly relies on the inspection of seismic damage to beam-column connections. Recently, in order to evaluate seismic damage of steel connections in a prompt and precise manner, a local damage evaluation method based on dynamic strain responses has been proposed and receives attention. In the evaluation method where strain responses are measured by piezoelectric strain sensors, a strain-based damage index has been developed for evaluating individual seismic beam damage in a steel frame. However, for a steel frame suffering multiple beam damages, the damage index deteriorates its performance in identifying small damages with the presence of neighboring severe damages due to the moment redistributions induced by larger damages. This paper presents a decoupling algorithm that removes the issue of damage interaction and improves the performance of the damage index. The decoupling algorithm was derived on the basis of damage-induced moment release and redistribution mechanism. The effectiveness of the decoupling algorithm was numerically and experimentally investigated using a nine-story steel frame model and a large scale five-story steel frame testbed that can simulate multiple fractures at beam ends.

KEY WORDS: damage quantification; seismic damage; steel moment-resisting frame; damage interaction; structural health monitoring; dynamic strain

\section{INTRODUCTION}

High-rise steel buildings that are subjected to long period ground motions likely suffer severe damage on steel beam-column connections, such as fracture, owing to strength deterioration under many cycles of inelastic deformation. This vulnerability was observed in the full scale shaking table tests of a high-rise steel building specimen conducted at the E-Defense facility in Japan [1, 2]. In addition, various numerical and experimental studies (e.g., Luco and Cornell [3], Rodgers and Mahin [4], Nakashima et al. [5], and Lignos et al. [6]) demonstrated that the occurrence of severe damage on beam-column connections may deteriorate the seismic capacity of steel buildings. Thus, in recent devastating earthquakes (e.g., the 2011 Tohoku earthquake in Japan), the strong sway of high-rise steel buildings excited by long period ground motions, raised considerable concerns about the post-earthquake safety of the buildings. In some cases, the lack of rapid and reliable information regarding the safety of buildings caused much disorder in the evacuation and re-occupancy.

Structural health monitoring (SHM), which enables structural engineers or owners to evaluate damage in structures in a prompt and objective manner, is acknowledged as one of promising tools to support rapid safety evaluation and decision-making for earthquake- 
affected buildings [7]. At present, a few important buildings located at metropolitan areas with high seismicity have installed SHM systems, where the global characteristics of buildings (e.g., acceleration responses, modal frequency and mode shape, and inter-story drift ratio) are primarily used for damage assessment [8-10]. Experimental investigations into the damage estimation using global characteristics demonstrated that they estimated the health conditions of buildings to some extent, but encountered serious challenges to give reliable information of seismic local damage on structural members that are critical for postearthquake safety evaluation. Accordingly, detection of local damage on structural members using a dense-array sensing system has received attention in recent years $[11,12]$.

In case of steel moment-resisting frames, they are prone to suffer fracture damage at welded beam ends when the strong-column and weak-beam philosophy is adopted in their design. In the 1994 Northridge and 1995 Kobe earthquakes, a large number of steel momentresisting frames suffered fractures at welded beam ends [13-15]. After the earthquakes, the inspection of fracture damage required extensive labor and costs involved in the removal of fireproofing and architectural finishes [16]. In this context, Kurata et al. [17] and Li et al. [18, 19] proposed a local damage evaluation method for steel moment-resisting frames using dynamic strain responses. In the method, the extent of beam fracture is quantified using a dynamic-strain-based damage index and an associated damage curve in which the reduction of bending stiffness at the fractured section is a function of the damage index. The method is reported to be very effective in identifying single damage but when a steel frame sustains multiple beam damages, the accuracy of damage estimation deteriorates due to the moment redistributions triggered by neighboring damages.

During the past few decades, several methods have been developed for identifying multiple damages in building structures. Sohn and Law [20] proposed a Bayesian probabilistic approach for detecting the most likely locations and extents of damages in multi-story frame structures. The approach was verified through numerical studies on several simple frame models where the damages were simulated as the deterioration of substructures. Shi et al. [21] developed a damage detection method based on modal strain energy change, which was experimentally investigated using a two-story and single-bay portal steel frame. Results indicated that the method was able to localize multiple damages, but the quantification of damages was only successful in low-level noise environments. Cha and Buyukozturk [22] proposed a multiple damage identification method based on modal strain energy and hybrid multiobjective optimization, which was examined using numerical studies of three complicated steel frame structures. The investigations indicated that the method was effective in detecting multiple damages but the performance deteriorated for small damage with incomplete and noise-contaminated mode shapes. The identification of multiple damages in building structures is still challenged, especially using experimental data.

This paper presents a decoupling algorithm for improving the accuracy of the dynamicstrain-based damage index proposed in [17-19] in the identification of multiple damages by removing the influence of neighboring damage interaction in moment redistributions. The decoupling algorithm was derived on the basis of the mechanism of damage-induced moment release and redistribution in frames. In the derivation, an analytical study on a simple subframe illustrated that the moment released by a beam fracture mainly distributes on the same floor levels and the influence to neighboring floors are small. The effectiveness of the decoupling algorithm was numerically studied using a nine-story steel moment-resisting frame model and experimentally examined using a large scale five-story steel frame testbed that can simulate multiple beam fractures.

\section{LOCAL DAMAGE EVALUATION METHOD}


In steel moment-resisting frames subject to earthquake loading, the bending moments sustained by a structural member decrease with a local damage of the member that reduces the member's stiffness. In practice, such changes in bending moments can be estimated using strain responses under ambient vibrations, assuming that the amplitude of the strain at a particular location of a member is proportional to the amplitude of the bending moment and structural members behave linearly. Thus, local damage on a structural member can be evaluated through a comparative study of strain responses of the member between the intact state and the damaged condition.

Figure 1 illustrates the schema of the local damage evaluation method presented in [17-19] for quantifying the damage extent of a beam seismic fracture that initiates at the toe of the weld access hole at beam-end in steel frames. As shown in Figure 1(a), a wireless strain sensing system that consists of a dense array of polyvinylidene fluoride (PVDF) sensors (DT1-028k, Measurement Specialties, VA, USA) [23] interfaced with Narada wireless sensing units (Civionics, LLC, CO, USA) [24] is deployed on a steel frame. Dynamic strain responses are measured under ambient vibrations before and after an earthquake. The sensing system includes a reference sensor and detecting sensors. The reference sensor is used to eliminate the effects of external excitations. A floor with small deformation where the concrete slabs and beams remain undamaged (e.g., the roof) is recommended for the location of the reference sensor. The detecting sensors are used to detect and quantify local damages on the damage-prone beams which are pre-identified using structural analysis. Detecting sensors are attached on both sides of beam bottom flanges at recommended locations where unaffected by the local redistribution of strains induced by damages. Li et al. [18] suggests the location as 1.5 beam depths away from column surfaces. In steel frames, the probability of sustaining fracture damage to beam-column connections increases as inter-story drift increases. Thus, several floors likely sustaining large inter-story drift (usually at the lower stories) have higher priority in the monitoring strategy.

The damage index $(D I)$ is defined as Equation (1) [18], which is formulated from a comparison of strain responses measured before and after an earthquake.

$$
D I=\frac{R_{j}^{d}-R_{j}}{R_{j}} \times 100 \%,
$$

where $R_{j}$ and $R_{j}^{d}$ are the ratios of strain responses associated with a natural mode-the $j$ th mode at the detecting and reference sensors under the undamaged condition and after an earthquake, respectively. In practice, the strain responses associated with the $j$ th mode are extracted using band-pass filters on strain time histories; ratios $R_{j}$ and $R_{j}^{d}$ are evaluated by the root mean square (RMS) of the filtered strain time histories. The damage index is proven to be independent of external excitations and vibrational modes. The damage index of less than 0 indicates the existence of damage on the monitored beam end. The damage index of $-100 \%$ means complete fracture. If the damage index is not less than 0 , there is no damage on the monitored beam end, and the damage index indicates the changes in the strain responses measured at the beam end induced by neighboring damages (see Figure 1(b)). When strain sensor is located in the region unaffected by the local strain redistribution, the damage index equals to the changes in the bending moments at the sensor location.

The damage extent of a seismic fracture at beam end is evaluated using the damage curve (see Figure 1(b)) expressed as Equation (2) that is presented in [19], 


$$
\rho=\frac{-\left(B_{2}(D I)-A_{2}\right)-\sqrt{\left(B_{2}(D I)-A_{2}\right)^{2}-4\left(B_{1}(D I)-A_{1}\right)\left(B_{3}(D I)-A_{3}\right)}}{2\left(B_{1}(D I)-A_{1}\right)},
$$

where $\rho$ is the reduction of the bending stiffness at the fractured section; $A_{1}, A_{2}, A_{3}, B_{1}, B_{2}$, and $B_{3}$ are coefficients that are functions of structural parameters. Note that the absolute value of the damage index is adopted alternatively in the damage curve. Using the expression of the damage curve, the reduction of bending stiffness of the damaged beam can be directly estimated from the damage index. The damage curve is limited for a single beam fracture in steel frames. This is how the local damage evaluation method estimates the damage extent of a seismic beam fracture.

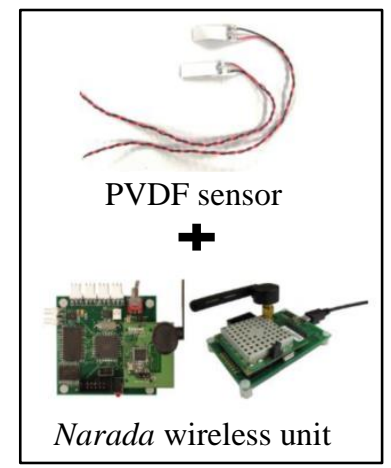

Strain sensing sensor

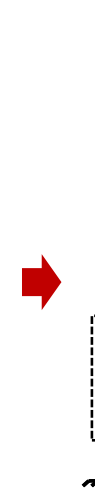

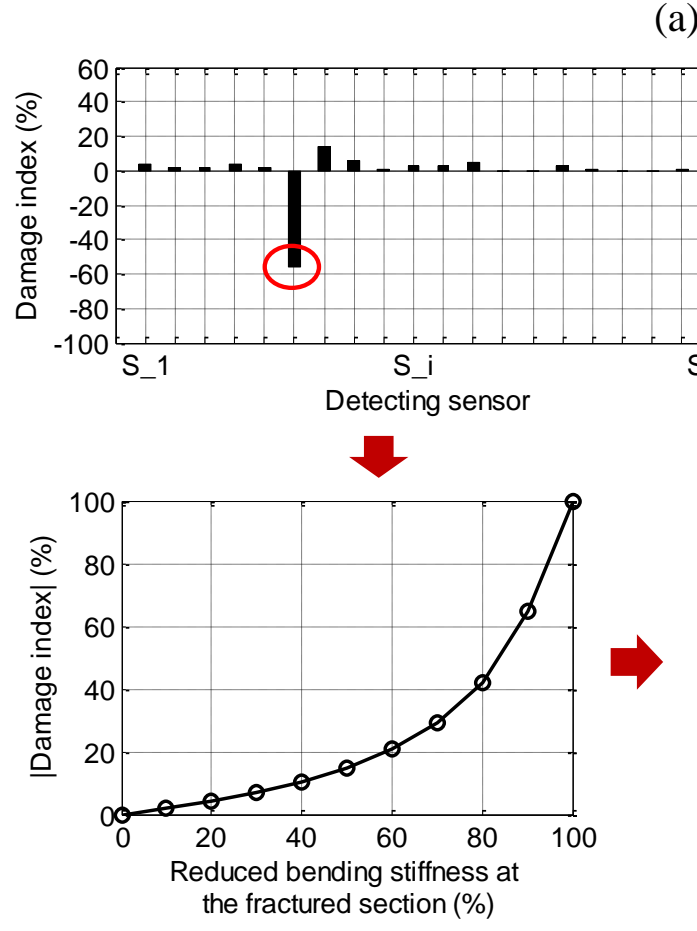

Damage curve

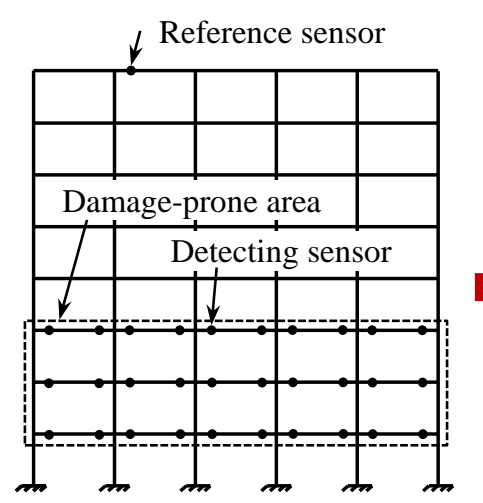

Steel frame

(a)

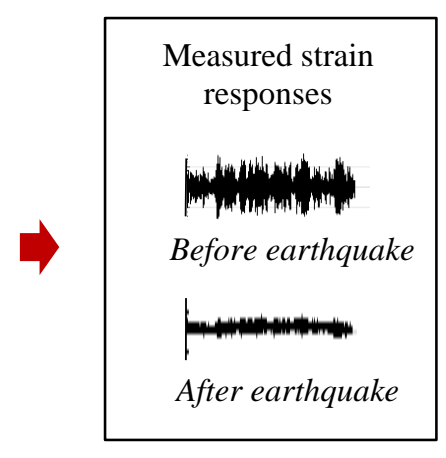

Strain data

Damage index

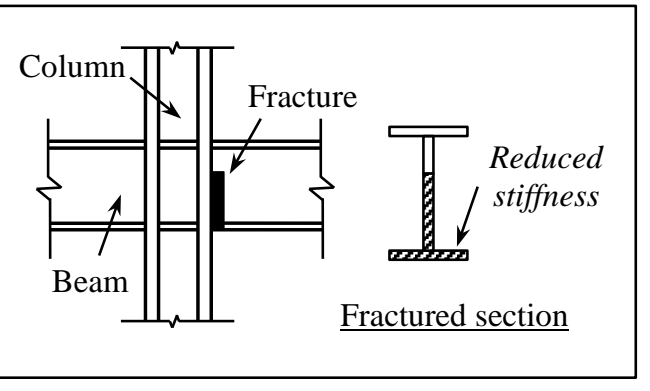

Fracture extent

(b)

Figure 1. Local damage evaluation method: (a) wireless strain sensing system on a steel frame; (b) quantification of a beam fracture using the damage index and the damage curve.

When a steel frame sustains multiple beam fractures, the strain responses measured at a damaged beam end increases by the neighboring damage-induced moment releases. Thus, the 
damage index for damage at a beam end increases with the existence of neighboring damages in the frame. Figure 2 illustrates a comparison of the damage indices for beam ends at a floor of a frame suffering two damage conditions. In the damage condition A, the right beam end of the interior beam-column connection at the second floor sustains the fracture damage D1, i.e., a $30 \%$ decrease in the bending stiffness. In the damage condition B, besides the damage D1 at the right beam end of the connection, the left beam end of the same connection sustains the fracture damage D2, i.e., an $80 \%$ decrease in the bending stiffness. In Figure 2(b), compared with the damage index of $-10.8 \%$ at sensor U3 for the single damage D1 in the condition A, the damage index increases by $19.5 \%$ for the same damage D1 in the condition B because of the influence of neighboring damage. As a result, the damage index is inaccurate in detecting the damage D1 in the condition B. In order to identify multiple beam fractures in steel frames, the influence of neighboring damages needs to be removed and thus the damage indices are identical to those associated with single damage conditions.

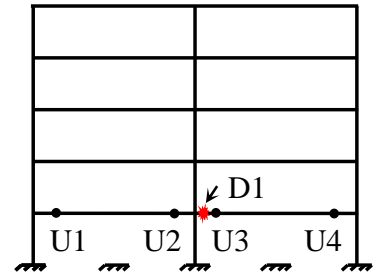

Condition A

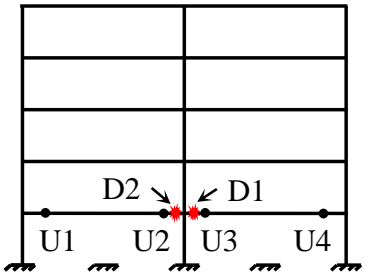

Condition B

(a)

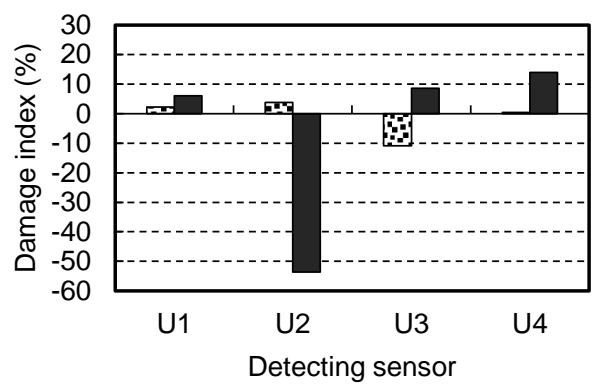

a Condition A - Condition B

(b)

Figure 2. Comparison of the damage index for the same damage between single and multiple damage conditions: (a) two damage conditions; (b) damage indices.

\section{DECOUPLING ALGORITHM}

This section presents a decoupling algorithm for removing the influence of neighboring damage interaction on the damage index. First, the mechanism of damage-induced moment release and redistribution in frames is analytically studied using a simple sub-frame. Then, a decoupling algorithm of estimating the damage index for multiple beam damages is formulated.

\subsection{Influence of damage-induced moment release}

Inclusion of beam damages in a steel moment-resisting frame results in the releases of the bending moments sustained by the beams and thus the released bending moments are redistributed in the frame [25]. The following analytical study on a simple sub-frame, which 
is extracted from a multi-story multi-bay frame, demonstrates the redistribution of released moments induced by a beam fracture.

A four-story four-bay sub-frame is considered as shown in Figure 3, where $k_{b}$ and $k_{c}$ are the bending stiffness of beams and columns, respectively; $h$ denotes the height of each story; $l$ is the width of each span. The bending moment $M_{A}$ is the release of the moment caused by the fracture damage at the beam end A. Assuming that the frame behaves linearly, the bending moments at the beam ends B, C, D, E, F, G, H, I, J, K, N, and O generated by the released moment $M_{A}$ are calculated by the displacement method for the analysis of indeterminate structures as follows,

$$
M_{i}=\delta_{i A} M_{A}=f_{i}(a) M_{A},(i=\mathrm{B}, \mathrm{C}, \mathrm{D}, \mathrm{E}, \mathrm{F}, \mathrm{G}, \mathrm{H}, \mathrm{I}, \mathrm{J}, \mathrm{K}, \mathrm{N}, \text { and } \mathrm{O})
$$

where $\delta_{i A}(i=\mathrm{B}, \mathrm{C}, \mathrm{D}, \mathrm{E}, \mathrm{F}, \mathrm{G}, \mathrm{H}, \mathrm{I}, \mathrm{J}, \mathrm{K}, \mathrm{N}$, and $\mathrm{O})$ are influence coefficients. The influence coefficients are constants, which indicate that the redistributed moments are proportional to the released moment. In addition, the influence coefficients only relate to the column-to-beam stiffness ratio $a\left(=k_{d} / k_{b}\right)$. Figure 4 illustrates the relationships between the influence coefficients $\delta_{i A}$ and the column-to-beam stiffness ratio $a$. The column-to-beam stiffness ratio ranges from 0 to 5 for common steel moment-resisting frames in this study. The influence coefficient $\delta_{E A}$ for the neighboring beam end $\mathrm{E}$ decreases from 1 to 0.1 as the stiffness ratio increases from 0 to 5 . The influence coefficient $\delta_{B A}$ is more than 0.3 for the beam end B on the same beam. The influence coefficients $\delta_{C A}, \delta_{D A}$ and $\delta_{F A}$ for the beam ends $\mathrm{C}, \mathrm{D}$ and $\mathrm{F}$ on the neighboring beams at the damaged floor are less than 0.3 . On the neighboring floor, the influence coefficients $\delta_{H A}, \delta_{I A}$, and $\delta_{J A}$ are at most 0.05 for the nearby beam ends $\mathrm{H}$, I, and J, while the influence coefficients $\delta_{G A}$ and $\delta_{K A}$ are at most 0.01 for the farther beam ends $\mathrm{G}$ and $\mathrm{K}$. On the non-adjacent floor, the influence coefficients $\delta_{N A}$ and $\delta_{O A}$ for the beam ends $\mathrm{N}$ and $\mathrm{O}$ are at most 0.01 (see Figure 4(b)). These findings imply that the released moment $M_{A}$ mainly distributes to the neighboring beam ends at the same floor level. The influence is at most $5 \%$ for the nearby beam ends on the neighboring floors, and negligible influence to other beam ends on the neighboring floors and to all beam ends on the non-adjacent floors.

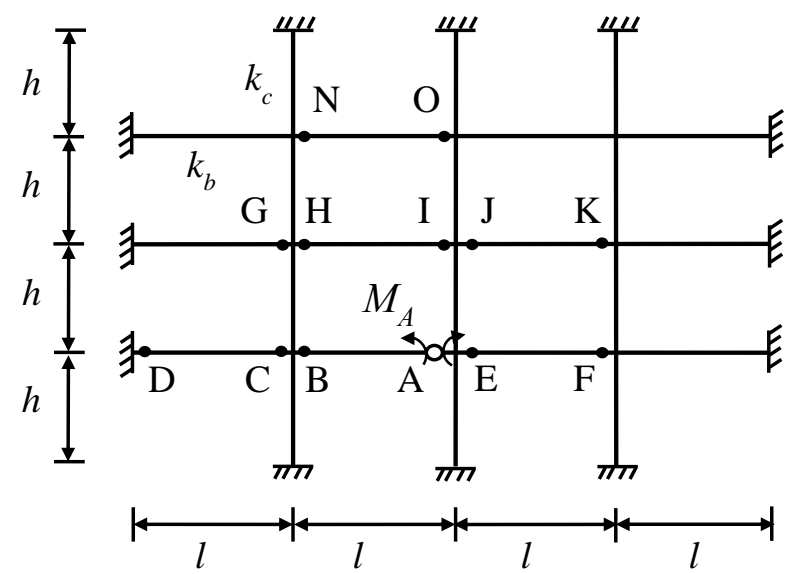

Figure 3. A sub-frame for studying moment release and influence. 


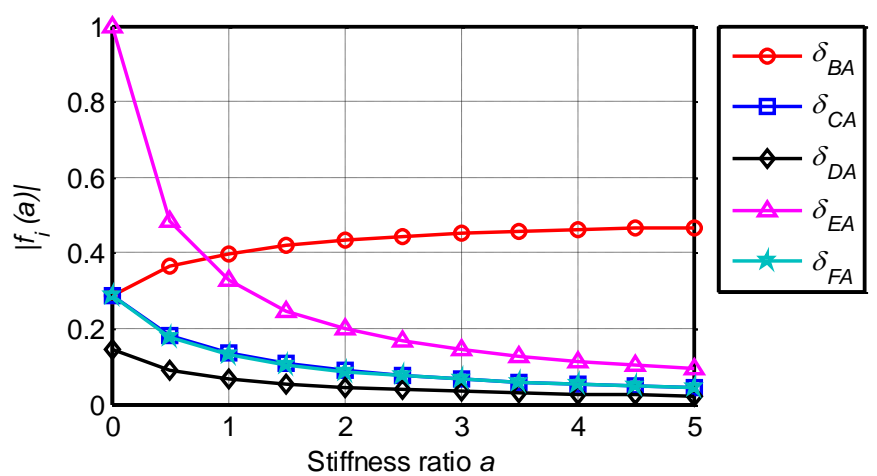

(a)

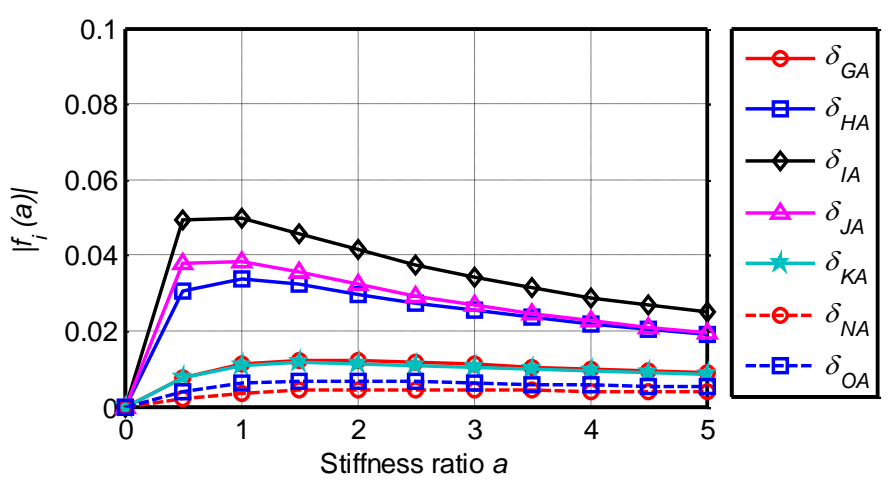

(b)

Figure 4. Relation between influence coefficient and column-to-beam stiffness ratio: (a) damaged floor; (b) upper floors.

In steel moment-resisting frames, when multiple beams suffer damages, damage-induced moment releases complicate the estimates on the bending moments of beams reduced by damages. Figure 5 shows the influence of moment releases on the reduced bending moments of a damaged beam in a frame. The released moments $M_{1}, M_{2}$, and $M_{3}$ are caused by three serious fracture damages nearby the damaged beam. All fractures reduce the stiffness of beam ends by $90 \%$. Without the influence of moment releases, the reduced bending moment at point A drops from 0 to $-100 \%$ as the reduced bending stiffness of the damage increases from 0 to $100 \%$. With the influence of the three moment releases $M_{1}, M_{2}$, and $M_{3}$, the reduced bending moments at point A change with increases from $4.2 \%$ to $14.4 \%$ (see Figure 5(b)). The increases for small damage are relatively larger than those for severe damage. Beam suffering small damage has less decrease in its stiffness and thus it sustains larger forces in the redistributions of moment releases. This indicates that the neighboring damage interaction largely affects the damage index of small damage, and has slight influence on the damage index for serious damage. 


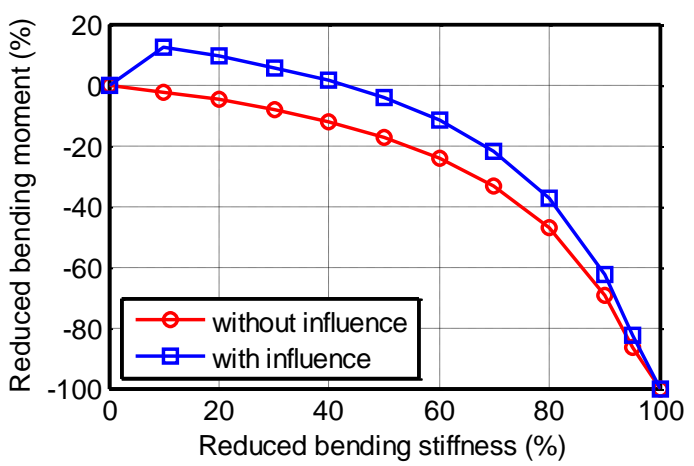

(b)

Figure 5. Influence of moment releases on reduced bending moments of a damaged beam: (a) a damaged frame; (b) reduced bending moments at point A.

\subsection{Decoupling algorithm}

As observed in the preceding analytical study, the damage-induced moment releases in steel moment-resisting frames mainly distributes at the same floor levels and the influence to other floors is very small (at the most 5\% to neighboring floors and negligible influence to nonadjacent floors). Thus, the interactions between beam damages located at two non-adjacent floors are assumed to be negligible. The damage interactions at the same floors are primarily considered to formulate a decoupling algorithm aiming to remove the influence of damageinduced moment releases on the presented damage index. Three consecutive floors of an $n$ span frame are modeled as shown in Figure 6(a). Each floor is sensed with $2 n$ strain sensors, e.g., sensors $S_{1, r}$ to $S_{2 n, r}$ placing for the $r$ th floor. The decoupling algorithm is formulated for beam damages on the $r$ th floor. In local damage evaluation, the damage index is identical to the changes of bending moments at a sensor location caused by damage of beam. Thus, according to the superposition principle, the damage indices measured on the $r$ th floor, which are coupled with each other, are equally expressed as a combination of the damage indices associated with individual beam damages on the $r$ th floor in addition to the influence from the moment releases of beam damages at two neighboring floors, i.e., the $(r-1)$ th and $(r+1)$ th floors, as follows,

$$
\boldsymbol{D I}=\Delta \overline{\mathrm{DI}}+(\boldsymbol{D I})^{\prime},
$$

$$
\boldsymbol{D I}=\left[\begin{array}{c}
(D I)_{1} \\
\vdots \\
(D I)_{i} \\
\vdots \\
(D I)_{2 n}
\end{array}\right] \quad \boldsymbol{\Delta}=\left[\begin{array}{ccccc}
\delta_{1,1} & \cdots & \delta_{1, j} & \cdots & \delta_{1,2 n} \\
\vdots & & \vdots & & \vdots \\
\delta_{i, 1} & \cdots & \delta_{i, j} & & \delta_{i, 2 n} \\
\vdots & & \vdots & & \vdots \\
\delta_{2 n, 1} & \cdots & \delta_{2 n, j} & \cdots & \delta_{2 n, 2 n}
\end{array}\right] \quad \overline{\boldsymbol{D I}}=\left[\begin{array}{c}
(\overline{D I})_{1} \\
\vdots \\
(\overline{D I})_{j} \\
\vdots \\
(\overline{D I})_{2 n}
\end{array}\right]
$$

where $\boldsymbol{D I}$ is a vector of measured damage indices at all sensors on the $r$ th floor; $\overline{\boldsymbol{D I}}$ is a vector of the damage indices associated with individual beam damages, named as decoupled damage indices; $\boldsymbol{\Delta}$ is an influence coefficient matrix, and $\delta_{i, j}(i=1, \ldots, 2 n, j=1, \ldots, 2 n)$ denotes the influence coefficients from $\mathrm{S}_{j, r}$ to $\mathrm{S}_{i, r}$ due to the moment release of the beam damage monitored by $\mathrm{S}_{j, r}$ (Figure 6(b)); (DI $)^{\prime}$ denotes the influence from the moment 


$$
(\boldsymbol{D I})^{\prime}=\sum_{q=1}^{m} \boldsymbol{\delta}_{q}(\overline{D I})_{q}=\sum_{q=1}^{m}\left[\begin{array}{c}
\delta_{1, q} \\
\vdots \\
\delta_{i, q} \\
\vdots \\
\delta_{2 n, q}
\end{array}\right](\overline{D I})_{q},
$$

where $\boldsymbol{\delta}_{q}$ denotes the influence coefficient vector for the influence from the damage on the ( $r-$ $1)$ th or $(r+1)$ th floors, in which $\delta_{i, q}(i=1, \ldots, 2 n)$ denotes the influence coefficient from sensor $\mathrm{S}_{q}$ to $\mathrm{S}_{i, r}$ due to the moment release of the beam damage monitored by $\mathrm{S}_{q}$ (Figure $6(\mathrm{c})) ;(\overline{D I})_{q}$ denotes the damage index corresponding to individual damage on the $(r-1)$ th or $(r+1)$ th floors. The $m$ denotes the number of beam damages on the $(r-1)$ th and $(r+1)$ th floors.

As mentioned before, the influence coefficients of moment releases from neighboring floors are at most 0.05. In addition, as illustrated in Figure 5(b), the neighboring moment releases cause the reduced bending moments of a damaged beam to increase by at most $15 \%$. This implies that the measured damage index of beam damage in multiple damage state is not largely different from the damage index corresponding to individual damage state. In Equation (5), thus, the measured damage index $(D I)_{q}$ of damages on the $(r-1)$ th or $(r+1)$ th $\underline{\text { floors can be used to compute the influence }}(\boldsymbol{D I})^{\prime}$ instead of the damage index $(\overline{D I})_{q}$ as follows.

$$
(\boldsymbol{D I})^{\prime}=\sum_{q=1}^{m} \boldsymbol{\delta}_{q}(\overline{D I})_{q} \approx \sum_{q=1}^{m^{\prime}} \boldsymbol{\delta}_{q}(D I)_{q}
$$

In some cases, the measured damage index of small damage is not less than 0 with the presence of neighboring damages and thus the damage is undetectable from the measured values. Therefore, the detectable damages on the $(r-1)$ th and $(r+1)$ th floors, i.e., the damage with the measured damage index of less than 0, are considered only in Equation (6). The $m^{\prime}$ denotes the number of detectable damages from measured damage indices on the $(r-1)$ th and $\underline{(r+1) \text { th floors. }}$

Given the measured damage indices of all sensors on the three consecutive floors, the decoupled damage indices associated with individual damages are expressed as,

$$
\overline{\boldsymbol{D I}}=\boldsymbol{\Delta}^{-1}\left[\boldsymbol{D I}-\sum_{q=1}^{m^{\prime}} \boldsymbol{\delta}_{q}(D I)_{q}\right]
$$

The influence coefficients $\delta_{i, j}(i=1, \ldots, 2 n, j=1, \ldots, 2 n)$ are the ratio of the damage indices of sensors $\mathrm{S}_{i, r}$ and $\mathrm{S}_{j, r}$ when the frame only suffers a damage at the beam end monitored by the sensor $\mathrm{S}_{j, r}$. These coefficients can be estimated using the moment release method with numerical models as the procedure below.

(1) Build a numerical model for a monitored steel moment-resisting frame.

(2) Set the releases of bending moments at the beam end monitored by the sensor $\mathrm{S}_{j, r}$ as unity.

(3) Compute the bending moments at the positions of sensors $\mathrm{S}_{i, r}$ and $\mathrm{S}_{j, r}$ induced by the moment releases. 
(4) Normalize the bending moment at the position of sensor $\mathrm{S}_{i, r}$ using that at the position of sensor $\mathrm{S}_{j, r}$ as influence coefficient $\delta_{i, j}$ (see Figure 6(b)).

When strain sensors are located around the beam ends, the influence coefficients can be estimated using the beam end moments instead of the moments sustained at the position of sensors.

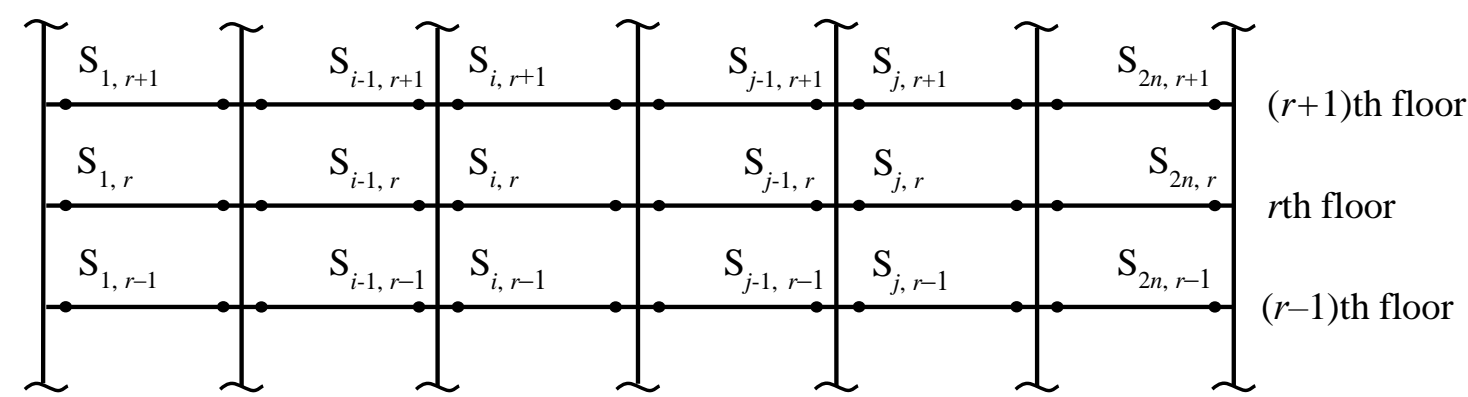

(a)

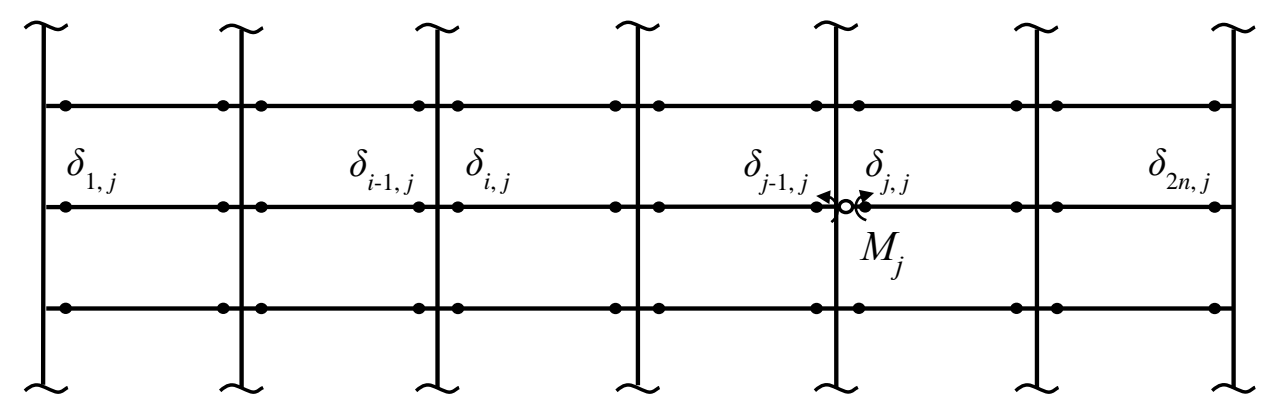

(b)

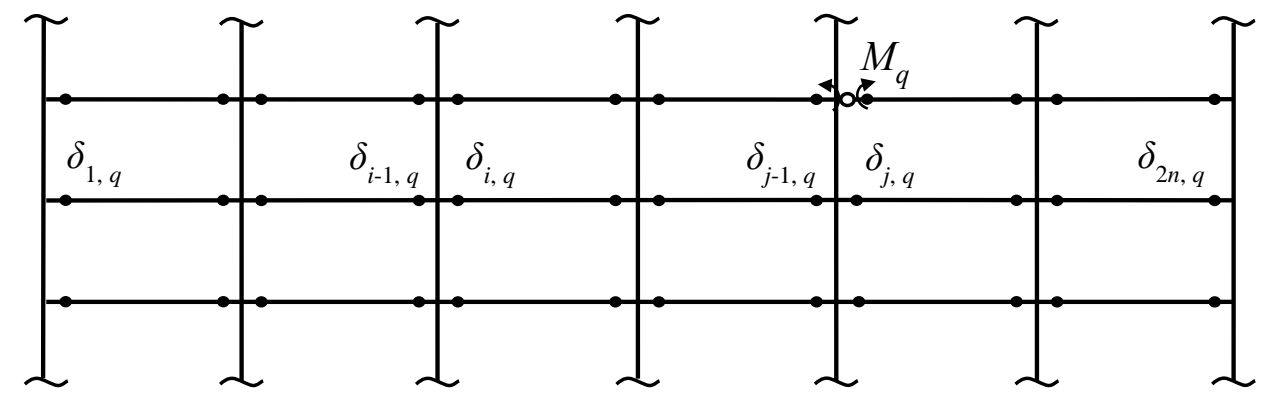

(c)

Figure 6. Three consecutive floors of an $n$-span frame: (a) sensors; (b) influence coefficients on the $r$ th floor; (c) influence coefficients for moment releases on the $(r+1)$ th floor.

\section{NUMERICAL VERIFICATIONS}

The effectiveness of the decoupling algorithm was examined through a numerical study of a nine-story steel moment-resisting frame (see Figure 7) designed for the SAC project and whose details were in FEMA-355C [26]. The numerical analysis was conducted using the SAP2000 software. In the numerical model, all members were modeled using beam elements. Beam fractures were simulated at beam ends by referring to the crack model proposed by Sinha et al. [27], where the fracture was modeled by a segment of beam whose stiffness was 
reduced to that of the fractured section; the length of the beam segment was determined as 0.75 beam depths for I-shaped beams. The damage index was extracted from the bending moment responses of beams using the extraction procedure reported in [17, 18].

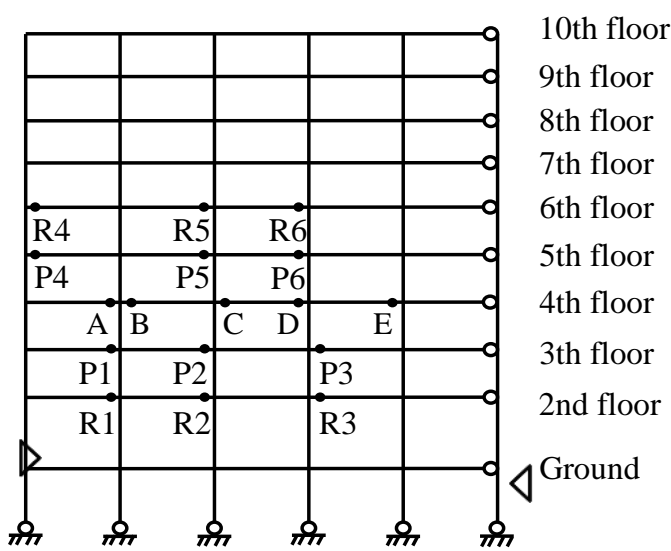

(a)

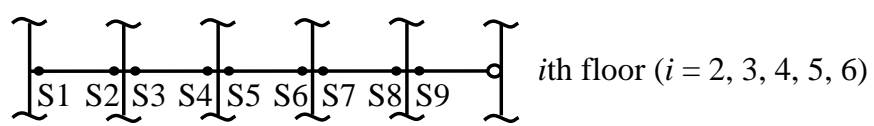

(b)

Figure 7. Nine-story steel moment-resisting frame: (a) frame; (b) sensor location.

The beam end $\mathrm{C}$ on the fourth floor (see Figure 7(a)) was damaged for studying the mechanism of damage-induced moment release. From the second to sixth floors, sensors S1 to S9 were placed on beams at 1.5 beam depths from the columns, as shown in Figure 7(b). Figure 8 shows the damage indices on the second to sixth floors when the damage reduced the bending stiffness by $90 \%$ at the beam end C. With the existence of a severe damage at the beam end $\mathrm{C}$, the damage index of sensor S5 near the damage was about $-70 \%$, while that of sensor S6 at another end of the same beam was about $-10 \%$. Moreover, the damage index of sensor S4 on the neighboring beam at the same floor was $21 \%$, and those of other sensors at the fourth floor varied from $5 \%$ to $10 \%$. By contrast, the damage index was less than $4 \%$ on the third and fifth floors, and less than $2 \%$ on the second and sixth floors (see Figure $8(\mathrm{~b})$ ). This indicates that the releases of the moment induced by the damage were primarily distributed at the neighboring beam ends on the same floor and the influence to the neighboring and farther floors was small.

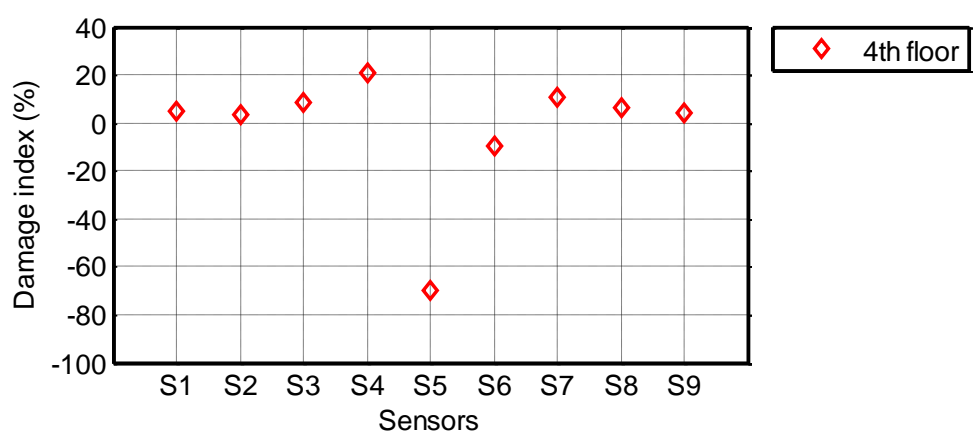

(a) 


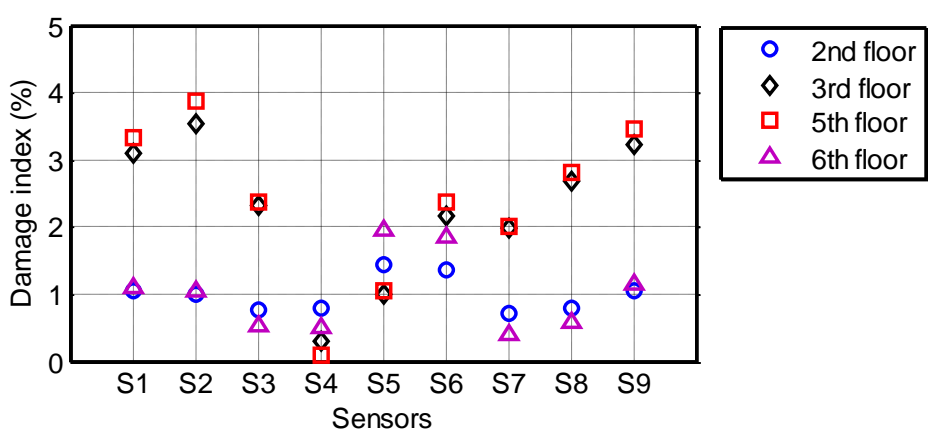

(b)

Figure 8. Distribution of the damage index on the second to six floors: (a) the fourth floor; (b) other floors.

Figure 9 shows the influence coefficients on the fourth floor for the damage at the beam end $\mathrm{C}$, in which the influence coefficients were obtained through the normalization of the damage indices and the calculation procedure, respectively. The damage indices on the fourth floor were normalized by that of sensor S5. Two levels of the damage, i.e., the decreases of $10 \%$ and $90 \%$ in the bending stiffness, were considered in the normalization of the damage indices. The influence coefficients were identical for two levels of the damage, which indicates that the influence coefficients do not relate to the damage extent. This also verifies that the damage-induced moment releases are linearly redistributed in frames as mentioned in the section 3.1. In addition, the influence coefficients calculated by the presented procedure were consistent with the values normalized from the damage indices, which imply that the calculation procedure was capable of calculating the influence coefficients.

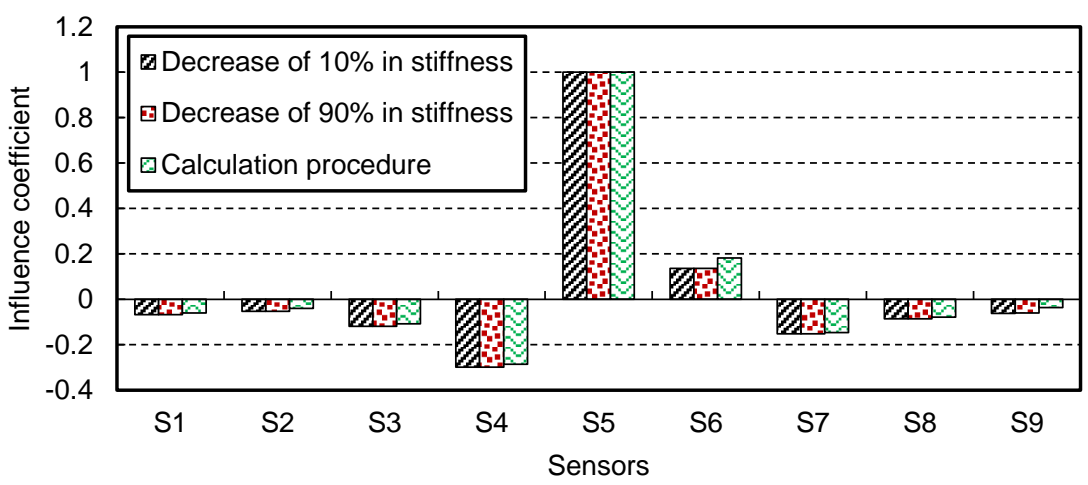

Figure 9. Influence coefficients on the fourth floor.

Seven damage cases in Table 1 were studied to examine the effectiveness of the decoupling algorithm. Seven damage cases can be sorted into four groups. Group 1 was used to verify the decoupling algorithm for multiple damages at an individual floor. Group 2 considered the influence of damages at the neighboring floors. Group 3 considered the influence of damages at the nonadjacent floors. Group 4 considered extremely damaged conditions. In all cases, five damages were simulated at the beam ends A, B, C, D, and E on the fourth floor (see Figure 7(a)). These damages reduced the bending stiffness of the beam ends by $50 \%, 70 \%, 30 \%, 30 \%$, and $80 \%$, respectively.

Group 1 -There is no damage on other floors.

Group 2 -Six damages are simulated at the beam ends P1 to P6 on the neighboring floors, i.e., the third and fifth floors (see Figure 7(a)). The damage reduces the bending stiffness of all beam ends by $50 \%$ in Case 2 , and $80 \%$ in Case 3. 
Group 3 -Six damages are simulated at the beam ends R1 to R6 on the nonadjacent floors, i.e., the second and sixth floors. The damages reduce the bending stiffness of all beam ends by $50 \%$ in Case 4 , and by $80 \%$ in Case 5.

Group 4 -Twelve damages are simulated at the beam ends P1 to P6 on the third and fifth floors and R1 to R6 on the second and sixth floors. In Case 6, the damages reduce the bending stiffness of all beam ends by $50 \%$. In Case 7, the damages reduce the bending stiffness by $50 \%$ at the beam ends P1 to P6, and by $80 \%$ at the beam ends R1 to R6.

Table 1 Damage cases

\begin{tabular}{cccc}
\hline \multirow{2}{*}{ Groups } & Cases & \multicolumn{2}{c}{ Locations (reduction of bending stiffness) } \\
\cline { 3 - 4 } Group 1 & Case 1 & A $(50 \%), \mathrm{B}(70 \%), \mathrm{C}(30 \%), \mathrm{D}$ & Other floors \\
& Case 2 & $(30 \%), \mathrm{E}(80 \%)$ & No damage \\
Group 2 & Case 3 & Same as Case 1 & P1 to P6 (50\%) \\
& Case 4 & Same as Case 1 & P1 to P6 (80\%) \\
Group 3 & Case 5 & Same as Case 1 & R1 to R6 (50\%) \\
& Case 6 & Same as Case 1 & R1 to R6 (80\%) \\
Group 4 & Case 7 & Same as Case 1 & P1 to P6 (50\%), R1 to R6 (50\%) \\
& Ca P6 (50\%), R1 to R6 (80\%) \\
\hline
\end{tabular}

Figure 10 illustrates the measured and decoupled damage indices of sensors on the fourth floor for all damage cases. In all damage cases, the measured damage indices hardly detected the damages at the beam ends $\mathrm{C}$ and $\mathrm{D}$. For instance, in Case 1, the measured damage indices of $-0.3 \%$ and $0.8 \%$ at sensor S5 and S6 encountered large challenges to identify the existence of the damages (see Figure 10(a)). By contrast, the decoupled damage indices clearly detected the damages at the beam ends $\mathrm{C}$ and $\mathrm{D}$ in all cases. In Case 1, the decoupled damage indices were $-7.6 \%$ and $-7.4 \%$ at sensor S5 and S6 for the damages at the beam ends C and D, which were almost identical to the expected values. In addition, in all cases, compared to the expected values, the measured damage indices had the difference of about $15 \%$ for the beam end $\mathrm{A}, 10 \%$ for the beam end $\mathrm{B}$, and $5 \%$ for the beam end $\mathrm{E}$. The decoupled damage indices well matched with the expected values at the beam ends $\mathrm{A}, \mathrm{B}$, and $\mathrm{E}$.

More specifically, in the Case 1 of Group 1, the largest absolute difference between the expected and decoupled damage indices for five damages was about $2 \%$. This indicates that the decoupling algorithm works very well for multiple damages on individual floors. In addition, the decoupled damage indices for the undamaged beam ends had the absolute difference of $3.5 \%$ on average compared with the excepted values.

In Group 2, in which the neighboring floors, i.e., the third and fifth floors, sustained damages, when the decoupled damage indices for the damages were compared to the expected values, the largest absolute difference was $2.5 \%$ in Case 2, and 3.9\% in Case 3 (Figure 10(b)). This indicates that the estimation method of the influence from damages of neighboring floors in the decoupling algorithm is effective. The measured damage index of damages on the neighboring floors can be used to compute the influence instead of the damage index corresponding to individual damage condition.

In Group 3, in which the nonadjacent floors, i.e., the second and sixth floors, sustained damages, the largest absolute difference between the expected and decoupled damage indices for five damages was $2.1 \%$ in Case 4, and $4.2 \%$ in Case 5 (Figure 10(c)), which verified that the influence from damages of nonadjacent floors is negligible in the decoupling algorithm.

In Group 4, the steel frame suffered a large number of damages at beam ends on the four neighboring floors. In Case 6, the decoupled damage indices for five damages on the fourth floor had the largest absolute difference of $4.4 \%$ at sensor S6 in comparison with the expected 
values. This means the decoupling algorithm is capable of estimating the damage index in a complicated situation where many neighboring and farther floors are damaged. Nonetheless, in Case 7, in which the second and sixth floors were seriously damaged, the decoupled damage indices had large difference for small damages at the beam ends $\mathrm{C}$ and $\mathrm{D}$ compared to the expected values. The decoupled damage indices were $-1.8 \%$ and $-1.0 \%$ at sensor S5 and S6 for the small damages at the beam ends C and D, which was not easy for the damage identification.

In summary, the suggested decoupling algorithm was effective in identifying multiple damages in steel frames but its performance slightly weakened for small damage in the extremely damaged conditions. Practically speaking, in the health monitoring of earthquakeaffected steel buildings, damage detection has more focus on light or moderate damage conditions rather than serious damage states because steel buildings designed well hardly sustain a large number of severe damages close to collapse.
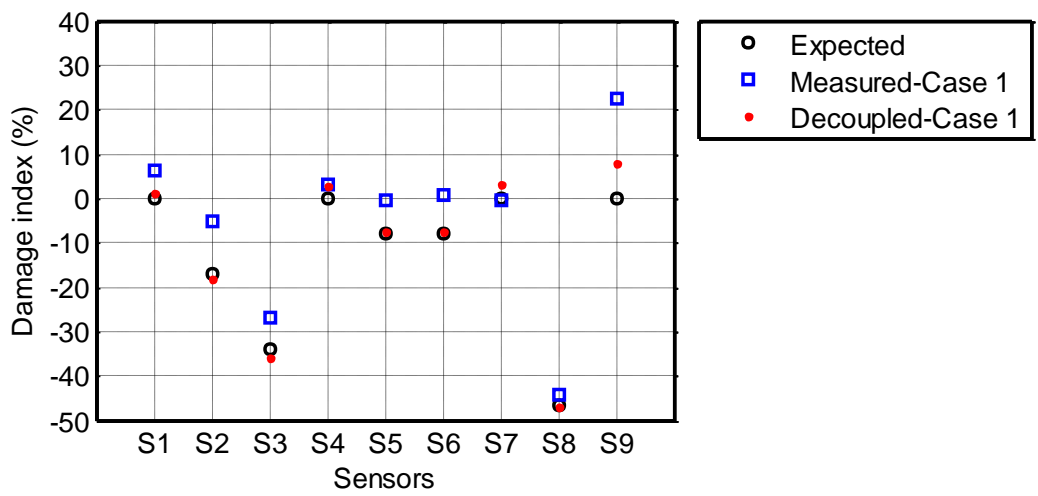

(a)
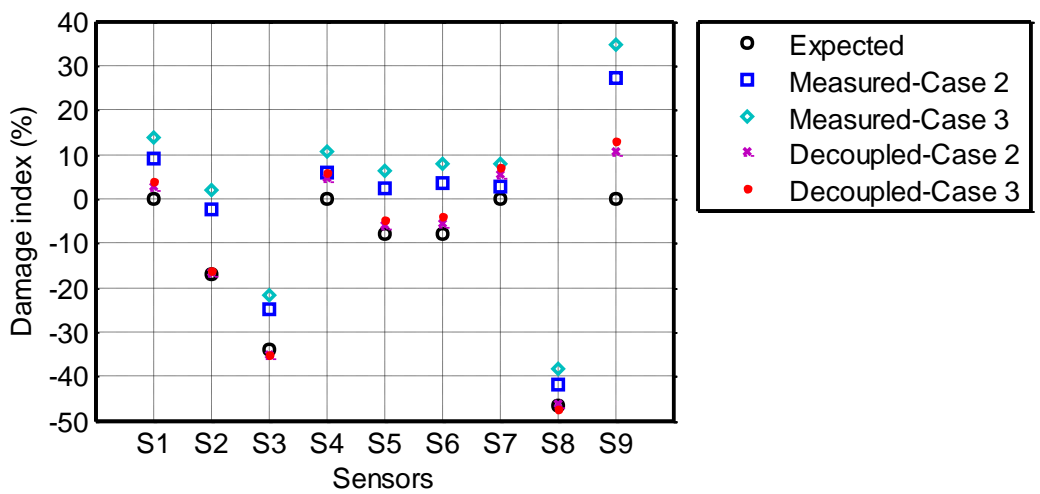

(b)
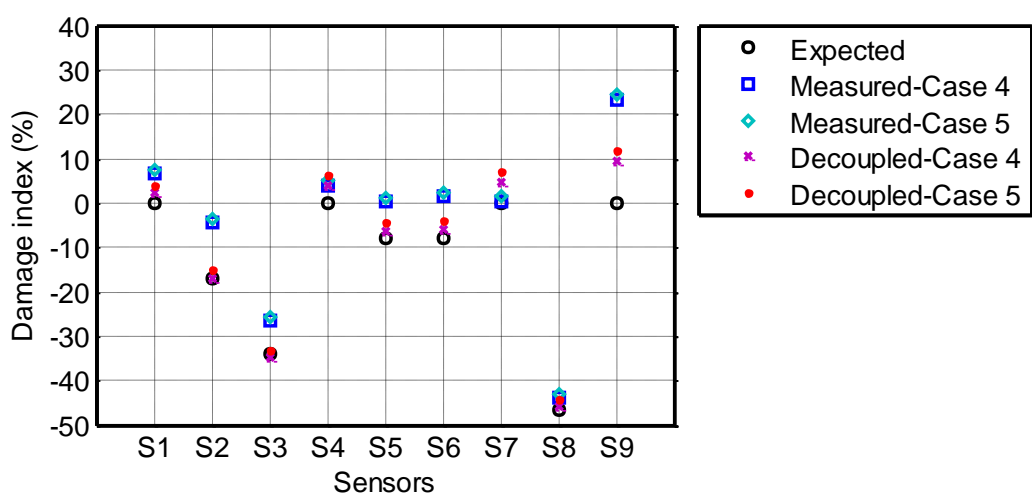

(c) 


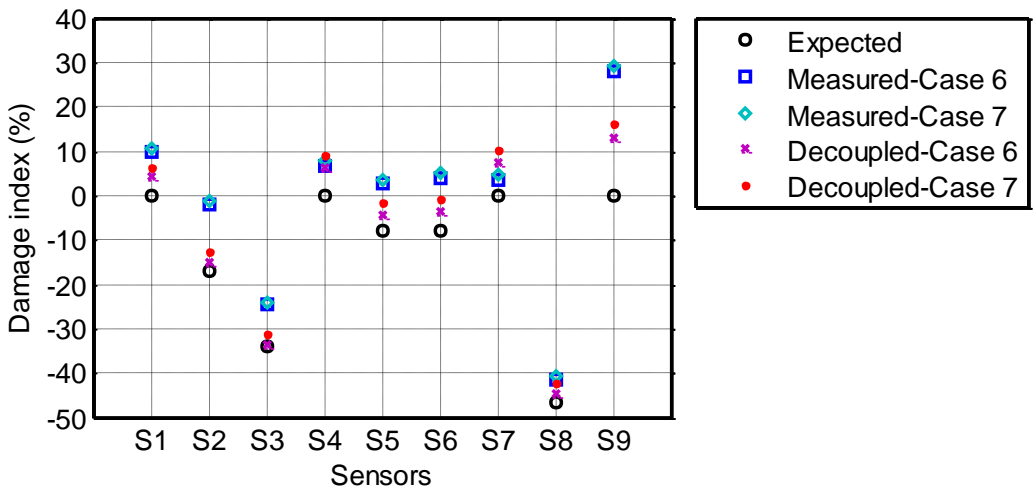

(d)

Figure 10. Measured and decoupled damage indices for multiple damages on the fourth floor: (a) Group 1; (b) Group 2; (c) Group 3; (d) Group 4.

\section{EXPERIMENTAL INVESTIGATIONS}

The decoupling algorithm of estimating damage indices for multiple damages was experimentally studied using a five-story steel frame testbed (see Figure 11(a)) constructed at the Disaster Prevention Research Institute (DPRI), Kyoto University. The dimensions of the testbed were $1.0 \times 4.0 \times 4.4 \mathrm{~m}$. Its plan was one bay by two bays. In each longitudinal steel frame, there were twelve steel removable connections at beam ends (i.e., connections B1 to B12, see Figure 11(b)), located at the second, third and fifth floors. Removable connection was made of four links at the flanges and one pair of links at the web (Figure 11(c)). The detailed information of the testbed was reported in Kurata et al. [17].

In vibrational testing, the testbed was excited using a modal shaker (APS-113, APS Dynamics) that was fixed to the steel mass plate on the fifth floor (Figure 11(d)). The strain responses of steel beams were measured using the wireless strain sensing system. PVDF strain sensors were placed on both sides of the beam bottom flange at 1.5 beam depths from the edge of the fracture. The damage index was extracted from the strain responses measured under small-amplitude white noise excitations (i.e., when the undamaged frame was excited, the roof acceleration responses were $3.32 \mathrm{~cm} / \mathrm{s}^{2}$ in RMS). Two PVDF strain sensors at the same beam section were treated as one sensor location as the average of the damage indices at two sides of the bottom flange was used in experimental investigations. There were 12 sensor locations, i.e., S1 to S12, located in the second to fourth floors, as shown in Figure 11(b).

By changing or removing the links, fracture damage was simulated. Figure 12 illustrates the undamaged state of the removable connection and three levels of fracture damage. Damage level 1 to level 3 (L1 to L3) simulated fracture of the whole bottom flange, fracture of the bottom flange and one-quarter of the web, and fracture of the bottom flange and half the web, respectively. As summarized in Table 2, the reduction in the bending stiffness about the major axis of the beam section was $53.4 \%$ for damage L1, $79.4 \%$ for damage L2, and $93.6 \%$ for damage L3.

Three tests including 9 damage cases were considered (Table 3) for the experimental investigation. In Test 1, damages L1 to L3 were simulated at the connection B1 for examining the mechanism of damage-induced moment release and redistribution. In Test 2, damage L3 was respectively simulated at four removable connections B1 to B4 to investigate the influence coefficients. In Test 3, two multiple damage cases were studied for the verification of the decoupling algorithm. Case 8 simulated two beam fractures at an individual floor; Case 9 simulated many fractures at two neighboring floors. 


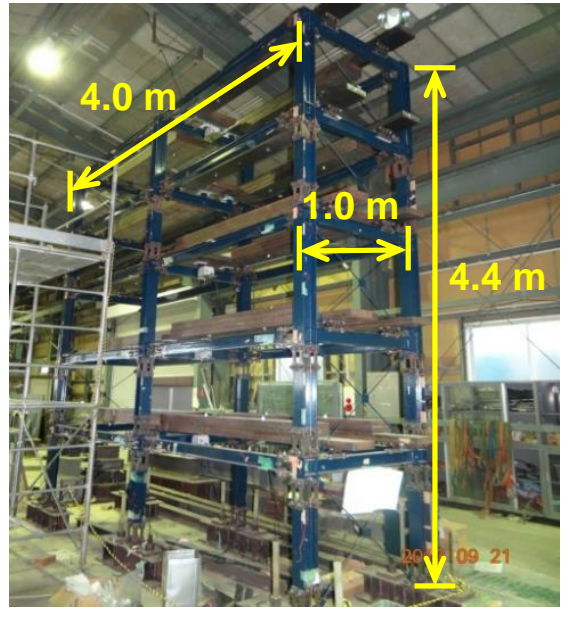

(a)

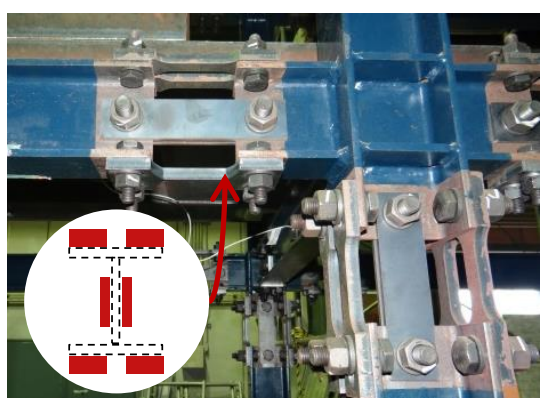

(c)

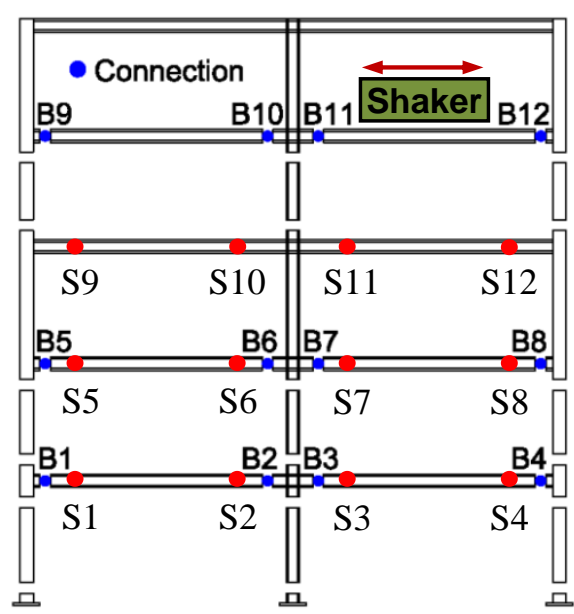

(b)

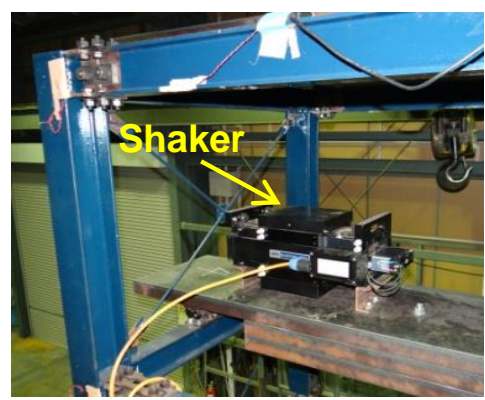

(d)

Figure 11. Five-story steel frame testbed: (a) overview; (b) beam connection and sensor location; (c) steel removable connection; (d) modal shaker [17, 18].

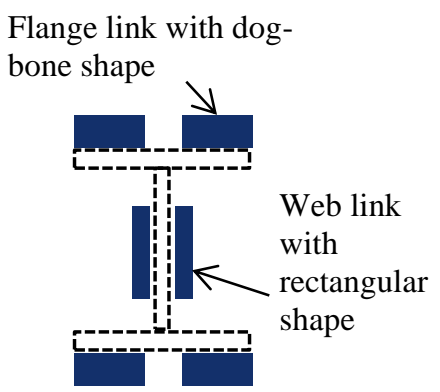

Undamaged

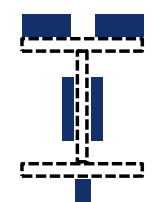

$\underline{\mathbf{L 1}}$

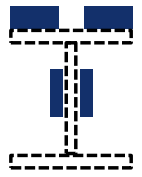

$\underline{\mathbf{L 2}}$

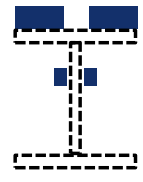

$\underline{\mathbf{L} 3}$

Figure 12. Undamaged state and damage patterns [19].

Table 2. Damage patterns [19].

\begin{tabular}{ccr}
\hline Damage pattern & Target of simulation & Reduction of $E I_{x}(\%)$ \\
\hline L1 & Fracture of whole bottom flange & 53.4 \\
L2 & Fracture of bottom flange and one-quarter web & 79.4 \\
L3 & Fracture of bottom flange and half web & 93.6 \\
\hline
\end{tabular}

Table 3. Damage cases in experimental investigation.

$\begin{array}{cccc}\text { Tests } & \begin{array}{c}\text { Damage } \\ \text { cases }\end{array} & \text { Connections (Damage patterns) Targets }\end{array}$




\begin{tabular}{|c|c|c|c|}
\hline \multirow{3}{*}{ Test 1} & Case 1 & B1 (L1) & \multirow{3}{*}{$\begin{array}{l}\text { Investigation of moment } \\
\text { release and influence }\end{array}$} \\
\hline & Case 2 & $\mathrm{~B} 1$ (L2) & \\
\hline & Case 3 & B1 (L3) & \\
\hline \multirow{4}{*}{ Test 2} & Case 4 & B1 (L3) & \multirow{4}{*}{$\begin{array}{l}\text { Investigation of influence } \\
\text { coefficients }\end{array}$} \\
\hline & Case 5 & B2 (L3) & \\
\hline & Case 6 & B3 (L3) & \\
\hline & Case 7 & B4 (L3) & \\
\hline \multirow[b]{2}{*}{ Test 3} & Case 8 & B2 (L3), B3 (L1) & \multirow{2}{*}{$\begin{array}{l}\text { Verification of the } \\
\text { decoupling algorithm }\end{array}$} \\
\hline & Case 9 & $\begin{array}{c}\mathrm{B} 1 \text { (L2), B3 (L1), B4 (L3), B5 } \\
\text { (L2), B8 (L3) }\end{array}$ & \\
\hline
\end{tabular}

Figure 13 illustrates the damage indices of 12 sensor locations for the damage L3 at the connection B1 in Case 1. When the bending stiffness of connection B1 decreased by $93.6 \%$, the damage index at sensor S1 was $-74.2 \%$. The damage index at other sensors on the same floor was at most $19.1 \%$ (see sensor S3), while the largest values of the damage index for the third and fourth floors were $8.0 \%$ at $\mathrm{S} 8$ and $0.9 \%$ at $\mathrm{S} 9$. This verified that the release of moment caused by beam damage mainly distributed on the same floor as demonstrated in the previous analytical studies and numerical analysis.

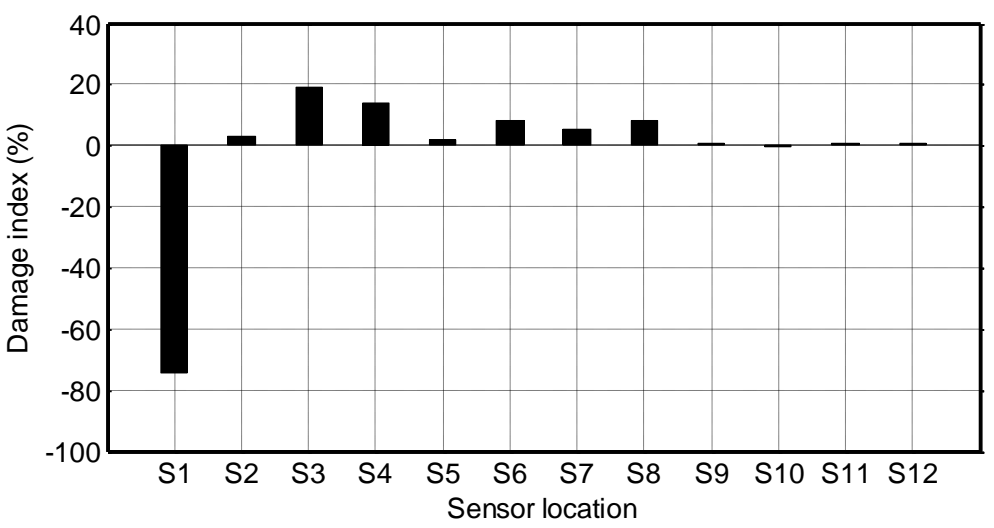

Figure 13. Distribution of the damage index in Case 1.

Figure 14 shows the normalized damage indices at four sensors S1 to S4 for three levels of the fracture damage (i.e., damages L1 to L3) simulated at the connection B1. The damage indices were normalized by the values of sensor S1. The normalized damage indices were nearly identical for three levels of the damage, which verifies the linear properties of the damage-induced moment release and redistribution.

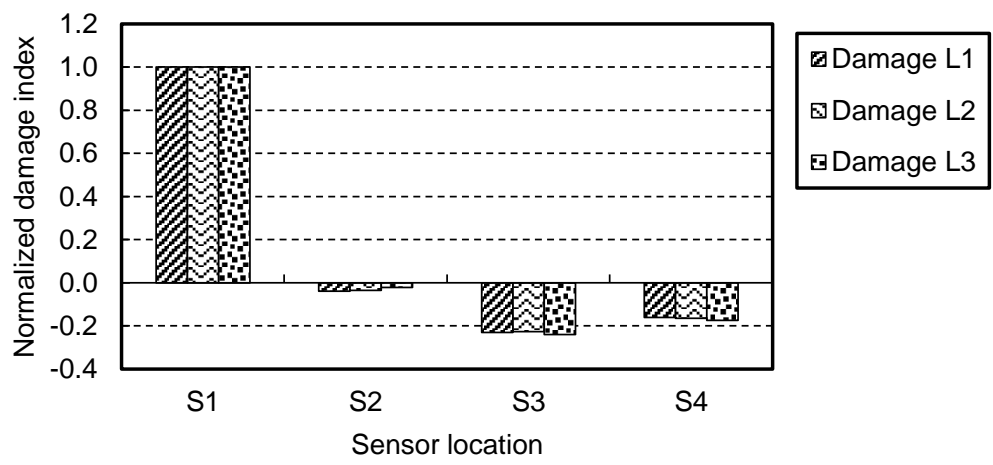

Figure 14. Normalized damage indices for three levels of fracture damage. 
In order to verify the presented procedure for calculating the influence coefficients, an experimental matrix $C_{e}$ of the influence coefficients (see Equation 8(a)) was obtained through the normalization of the damage indices in Test 2. The damage indices at four sensors $\mathrm{S} 1$ to S4 were normalized by the damage index at the sensor near the simulated damages. For example, the first column of $C_{e}$ was calculated by normalizing the damage indices at sensors $\mathrm{S} 1$ to $\mathrm{S} 4$ using the damage index at sensor S1 when the connection B1 sustained damage L3 in Case 4. The matrix $C_{p}$ of the influence coefficients (see Equation 8(b)) was obtained using the presented calculation procedure. When the matrix $C_{p}$ was compared with the experimental matrix $C_{e}$, only the influence coefficient $C_{p}(4,2)$ had obvious differences.

$$
C_{e}=\left[\begin{array}{cccc}
1.00 & -0.01 & -0.14 & -0.19 \\
-0.04 & 1.00 & -0.38 & -0.26 \\
-0.26 & -0.32 & 1.00 & -0.04 \\
-0.19 & -0.08 & -0.07 & 1.00
\end{array}\right]
$$

$$
C_{p}=\left[\begin{array}{cccc}
1.00 & -0.06 & -0.19 & -0.22 \\
-0.04 & 1.00 & -0.31 & -0.25 \\
-0.25 & -0.31 & 1.00 & -0.04 \\
-0.22 & -0.19 & -0.06 & 1.00
\end{array}\right]
$$

Figure 15 illustrates the measured and decoupled damage indices at four sensors S1 to S4 in Test 3. In Case 8, two fractures were simulated at neighboring connections B2 and B3. In this case, the fracture L1 at connection B3 could not be detected from the measured damage index of $11.7 \%$ (see Figure 15(a)), while the fracture was easily detected using the decoupled damage index of $-16.5 \%$ (Figure 15(b)). In Case 9, fracture damages were simulated at connections B1, B3 and B4 on the second floor and connections B5 and B8 on the third floor. Without the use of the decoupling algorithm, damage L2 and L3 at connections B1 and B4 were detected as the measured damage indices of $-30.9 \%$ and $-70.6 \%$ respectively, while damage L1 at connection B3 was not identified from the measured damage index of $13.8 \%$ (Figure 15(c)). In comparison, with the application of the decoupling algorithm, the damage L1 at connection B3 was identified by the decoupled damage index of $-14.9 \%$ (Figure 15(d)).

Figure 16 shows a comparison between the expected and decoupled damage indices at sensors S1 to S4 in Case 9. The expected values were extracted from tests of individual damage conditions. Compared with the expected damage indices, the damage indices decoupled with experimental matrix $C_{e}$ had the absolute differences of about $2 \%$ at sensor S2 and S3, and that of about $11 \%$ at sensors S1 and S4. This indicates that the decoupling algorithm was effective in estimating the damage indices for multiple damage conditions. In addition, the damage indices were nearly identical for the uses of the experimental matrix $C_{e}$ and analytical matrix $C_{p}$ in the decoupling algorithm, which implies that the presented procedure worked well in calculating the influence coefficients. 


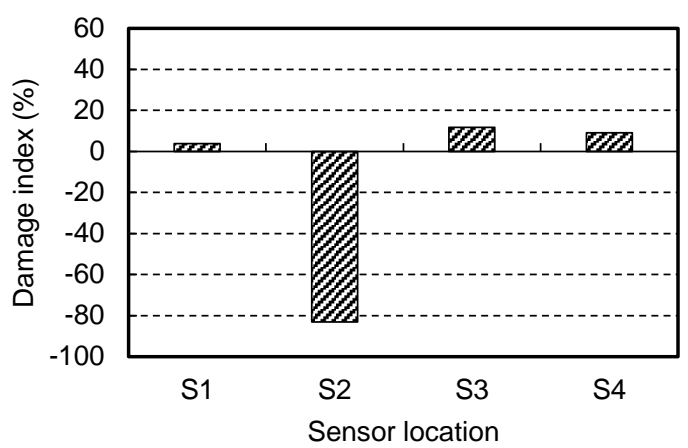

(a)

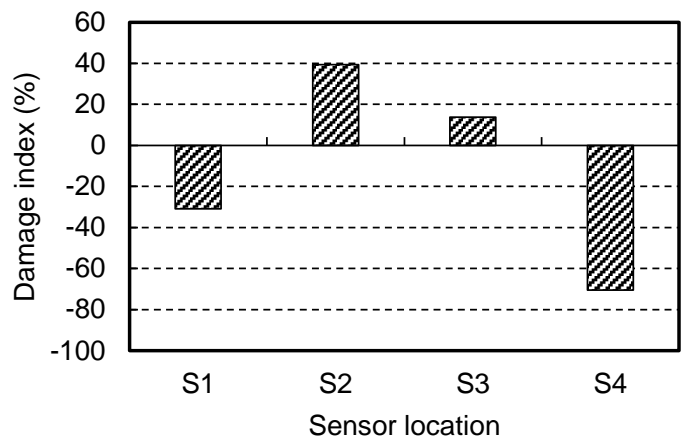

(c)

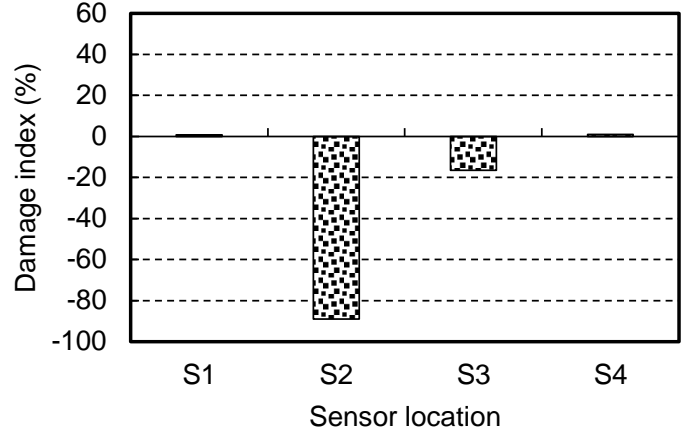

(b)

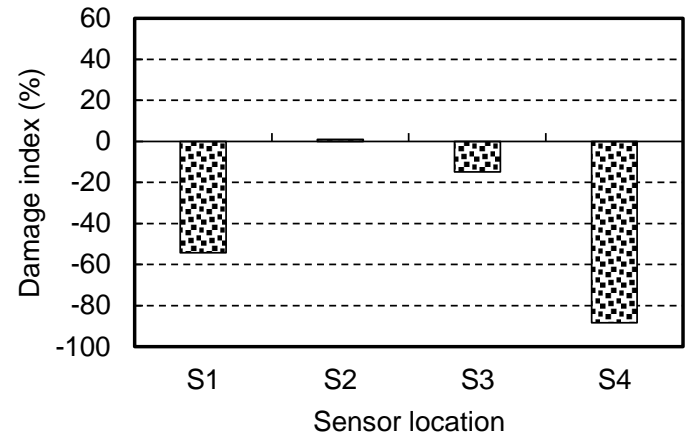

(d)

Figure 15. Measured and decoupled damage indices of sensors S1 to S4 on the second floor in Test 3: (a) measured damage indices in Case 8; (b) damage index decoupled with $C_{e}$ in Case 8; (c) measured damage indices in Case 9; (d) damage index decoupled with $C_{e}$ in Case 9.

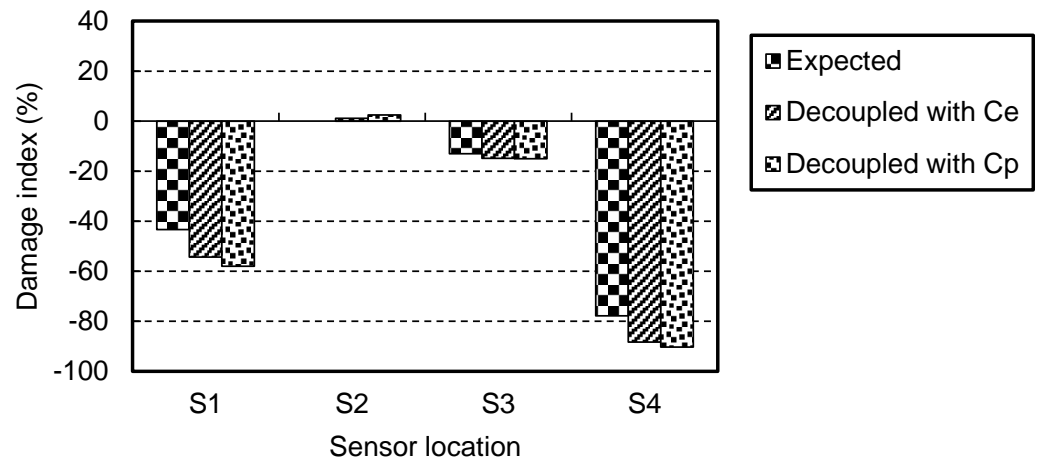

Figure 16. Expected and decoupled damage indices of sensors S1 to S4 on the second floor in Case 9.

Figure 17 illustrates the estimated reduction of bending stiffness for fracture damages on the second floor in Case 9. The reduction of bending stiffness evaluated from the expression of the damage curve, i.e., Equation (2), using the expected and decoupled damage indices. Compared with the values estimated from the expected damage indices, the values estimated from the damage indices decoupled with $C_{e}$ (or $C_{p}$ ) had the largest absolute difference of about $5 \%$. When the values estimated from the damage indices decoupled with $C_{e}$ were compared with the exact values calculated from the sectional properties, the differences were $7.7 \%$ for damage L2 at connection B1, $7.9 \%$ for damage L1 at connection B3, and $2.9 \%$ for damage L3 at connection B4. The relatively large difference for damage L1 at connection B3 
602

603

604

605

606

607

608

609

610

611

612

613

614

615

616

617

618

619

620

621

622

623

624

625

626

627

628

629

630

631

632

633

634

635

636

637

638

639

640

641

resulted from the expression of the damage curve which slightly underestimated fractures on bottom flanges as mentioned in [19].

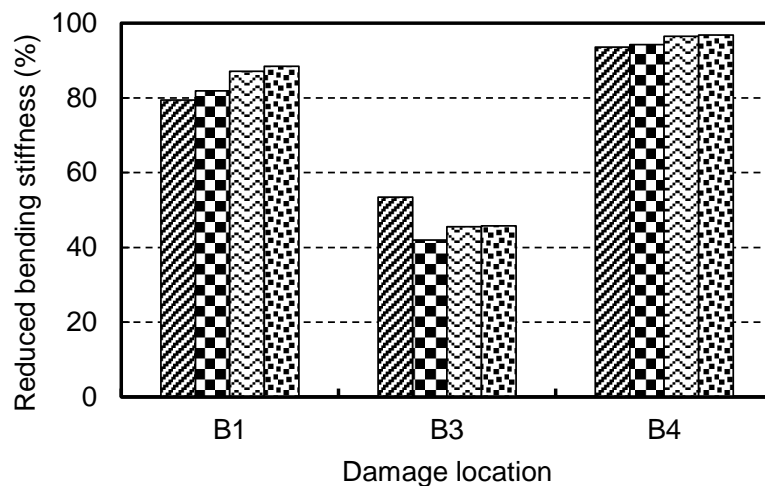

Exact value

avvaluated from expected DI

■Evaluated from decoupled DI-Ce

G Evaluated from decoupled DI-Cp

Figure 17. Estimated reduction of bending stiffness for fracture damages on the second floor in Case 9.

\section{CONCLUSIONS}

This paper presented a decoupling algorithm of removing the influence of the neighboring damage interaction for accurately estimating the damage indices of multiple beam damages in steel moment-resisting frames. The decoupling algorithm was derived on the basis of the mechanism of damage-induced moment release and a model of three consecutive floors of a frame. The effectiveness of the decoupling algorithm was verified through numerical studies of a nine-story steel moment-resisting frame and vibrational tests of a large-scale five-story steel frame.

In the derivation, the analytical study of the four-story four-bay sub-frame illustrated that damage-induced moment releases in steel frames mainly distributes at the same floor levels, and the influence to other floors is at the most 5\% to neighboring floors and negligible influence to non-adjacent floors. In addition, the moment releases largely affect the damage index of neighboring small damage, and has slight influence on the damage index for neighboring serious damage.

In numerical studies, the decoupling algorithm was very effective in identifying moderate and severe damages in all considered multiple damage conditions. For small damage which was hardly detected by the measured damage index, the decoupled damage index had powerful capability to identify it in most cases, but its performance slightly weakened in the extremely damaged states.

In experimental investigations, with the application of the decoupling algorithm, the accuracy of the damage indices for multiple beam damages was largely improved. The extent of the beam damage was successfully estimated using the decoupled damage index with the error of about $7 \%$. Therefore, the decoupling algorithm facilitates the application of the proposed local damage evaluation method for monitoring the conditions of steel momentresisting frames affected by earthquakes.

\section{ACHKNOWLEDGMENTS}

This work was supported by JSPS KAKENHI Grant Number 26820230 and by the General Collaborative Research program of the Disaster Prevention Research Institute, Kyoto 
University. The authors want to express their sincere gratitude to Dr. Yongtao Bai, and Ms. Kaede Minegishi for their assistance in the vibration tests.

\section{REFERENCES}

1. Chung Y, Nagae T, Hitaka T, Nakashima M. Seismic resistance capacity of high-rise buildings subjected to long-period ground motions: E-Defense shaking table test. Journal of Structural Engineering 2010; 136(6), 637-644. DOI: 10.1061/(ASCE)ST.1943541X.0000161.

2. Chung YL, Nagae T, Matsumiya T, Nakashima M. Seismic capacity of retrofitted beamcolumn connections in high-rise steel frames when subjected to long-period ground motions. Earthquake Engineering \& Structural Dynamics 2012; 41(4), 735-753. DOI: 10.1002/eqe.1154.

3. Luco N, Cornell A. Effects of connection fractures on SMRF seismic drift demands. Journal of Structural Engineering 2000; 126(1), 127-36. DOI: 10.1061/(ASCE)07339445(2000)126:1(127).

4. Rodgers J, Mahin S. Effects of connection fractures on global behavior of steel moment frames subjected to earthquakes. Journal of Structural Engineering 2006; 132(1), 78-88. DOI: 10.1061/(ASCE)0733-9445(2006)132:1(78).

5. Nakashima M, Matsumiya T, Suita K, Zhou F. Full-scale test of composite frame under large cyclic loading. Journal of Structural Engineering 2007; 133(2), 297-304. DOI: 10.1061/(ASCE)0733-9445(2007)133:2(297).

6. Lignos DG, Chung Y, Nagae T, Nakashima M. Numerical and experimental evaluation of seismic capacity of high-rise steel buildings subjected to long duration earthquakes. Computers \& Structures 2011; 89(11-12), 959-967. DOI: 10.1016/j.compstruc.2011.01. 017.

7. Celebi M, Sanli A, Sinclair M, Gallant S, Radulescu D. Real-time seismic monitoring needs of a building owner - and the solution: a cooperative effort. Earthquake Spectra 2004; 20(2), 333-346. DOI: 10.1193/1.1735987.

8. Morita K, Teshigawara M, Hamamoto T. Detection and estimation of damage to steel frames through shaking table tests. Structural Control and Health Monitoring 2005; 12(34), 357-380. DOI: $10.1002 /$ stc. 75 .

9. Naeim F, Hagie H, Alimoradi A, Miranda E. Automated post-earthquake damage assessment and safety evaluation of instrumented buildings. A Report to CSMIP (JAMA Report No. 2005-10639), John A. Martin \& Associates, 2005.

10. Kalkan E, Banga K, Ulusoy HS, Fletcher JPB, Leith WS, Reza S, Cheng T. Advanced earthquake monitoring system for U.S. Department of Veterans Affairs medical buildings - instrumentation. U.S. Geological Survey Open-File Report 2012-1241, 143 p, 2012.

11. Lynch PJ. Design of a wireless active sensing unit for localized structural health monitoring. Structural Control and Health Monitoring 2005; 12(3-4), 405-423. DOI: $10.1002 /$ stc. 77 .

12. Nigro MB, Pakzad SN, Dorvash S. Localized structural damage detection: a change point analysis. Computer-Aided Civil and Infrastructure Engineering 2014; 29(6), 416-432. DOI: 10.1111/mice. 12059 .

13. Nakashima M. Reconnaissance report on damage to steel buildings structures observed from the 1995 Hyogoken-Nanbu (Hanshin/Awaji) earthquake, Abridged English edition. Steel Committee of Kinki Branch, the Architectural Institute of Japan (AIJ), 1995. 
691

692

693

694

695

696

697

698

699

700

701

702

703

704

705

706

707

708

709

710

711

712

713

714

715

716

717

718

719

720

721

722

723

724

725
14. Youssef NFG, Bonowitz D, Gross JL. A survey of steel moment-resisting frame buildings affected by the 1994 Northridge earthquake. NISTR-5625, Gaithersburg, MD, 1995.

15. Mahin S. Lessons from damage to steel buildings during the Northridge earthquake. Engineering Structures 1998; 20(4-6), 261-270. DOI: 10.1016/S0141-0296(97)00032-1.

16. Gates W, Morden M. Lessons from Inspection, Evaluation, repair and construction, surveys and assessment of damage to buildings affected by the Northridge earthquake. Report SAC 95-06 (Sacramento: SAC Joint Venture), 1995.

17. Kurata M, Li X, Fujita K, Yamaguchi M. Piezoelectric dynamic strain monitoring for detecting local seismic damage in steel buildings. Smart Materials and Structures 2013; 22(11), 115002. DOI:10.1088/0964-1726/22/11/115002.

18. Li X, Kurata M, Nakashima M. Evaluating damage extent of fractured beams in steel moment-resisting frames using dynamic strain responses. Earthquake Engineering \& Structural Dynamics 2015; 44(4), 563-581. DOI: 10.1002/eqe.2536.

19. Li X, Kurata M, Nakashima M. Simplified derivation of a damage curve for seismically induced beam fracture in steel moment-resisting frames. Journal of Structural Engineering 2016; in press. DOI: 10.1061/(ASCE)ST.1943-541X.0001473.

20. Sohn H, Law KH. A Bayesian probabilistic approach for structure damage detection. Earthquake Engineering \& Structural Dynamics 1997; 26(12), 1259-1281. DOI: 10.1002/(SICI)1096-9845(199712)26:12<1259::AID-EQE709>3.0.CO;2-3.

21. Shi Z, Law S, Zhang L. Structural damage detection from modal strain energy change. Journal of Engineering Mechanics 2000; 126(12), 1216-1223. DOI: 10.1061/(ASCE)07339399(2000)126:12(1216).

22. Cha YJ, Buyukozturk O. Structural damage detection using modal strain energy and hybrid multiobjective optimization. Computer-Aided Civil and Infrastructure Engineering 2015; 30(5), 347-358. DOI: 10.1111/mice.12122.

23. Measurement Specialties. http://www.meas-spec.com [30 Dec. 2015].

24. Civionics, LLC. http://www.civionics.com [30 Dec. 2015].

25. Nakashima M, Minami T, Mitani I. Moment redistribution caused by beam fracture in steel moment frames. Journal of Structural Engineering 2000; 126(1), 137-144. DOI: 10.1061/(ASCE)0733-9445(2000)126:1(137).

26. FEMA-355C. State of the art report on systems performance of steel moment frames subject to earthquake ground shaking, 2000.

27. Sinha JK, Friswell MI, Edwards S. Simplified models for the location of cracks in beam structures using measured vibration data. Journal of Sound and Vibration 2002; 251(1):1338. DOI: $10.1006 /$ jsvi.2001.3978. 